\title{
Mesenteric cyst as a cause of sudden abdominal pain
}

\author{
Juan M. Dávila-Vega ${ }^{1}$, Amador Ramírez-Reséndiz², Raúl Hinojos-Flotte ${ }^{1}$,Rogelio Sánchez-Soriano, \\ Arturo Cervantes-Bárcenas ${ }^{1}$, and Julio C. López-Valdés ${ }^{1,3,4}$
}

${ }^{1}$ Department of General Surgery, Hospital Regional Río Blanco, Río Blanco, Veracruz; ${ }^{2}$ Department of Pediatric Oncology Surgery, Hospital Regional Río Blanco, Río Blanco, Veracruz; ${ }^{3}$ Department of Research, School of Medicine "Dr. Alberto Romo Caballero,"Universidad Autónoma de Tamaulipas, Tampico, Tamaulipas; ${ }^{4}$ Research Deparment, Cognitive Science S.A., Mexico City. México

\begin{abstract}
Mesenteric cysts are infrequent and can be located anywhere in the gastrointestinal tract. They can be single or multilocular and measure up to $30 \mathrm{~cm}$ in diameter. A 14-year-old female presented with pain in the left iliac fossa. Physical examination revealed a movable and painful tumor, not adhering to deep planes, of $15 \mathrm{~cm} \times 15 \mathrm{~cm}$. On surgical intervention, the report was as follows: a mesentery cyst $30 \mathrm{~cm}$ long, adhered to the greater curvature of the stomach, lodged in the pelvic hollow and left iliac fossa. This report exemplifies a case concordant with a mesentery cyst in an unusual location.
\end{abstract}

Key words: Mesentery. Mesentery cyst. Lymphatics. Small intestine. Resection.

\section{Introduction}

The presence of mesenteric cysts is rare. Medical literature reports an incidence of approximately $1 / 100,000-250,000$, and in pediatric populations, estimations suggest an incidence of 1/20,000 children ${ }^{1-5}$. They are more common among females in their 20 s and can be found anywhere in the gastrointestinal tract from the duodenum to the rectum. However, they occur more frequently in the small intestine $(66 \%)^{5}$. Its extension can vary from the base of the mesentery to the retroperitoneum and can be single or multilocular and measure up to $30-35 \mathrm{~cm}$ in diameter ${ }^{5-7}$. Cystic fluid is usually serous when it affects the distal small intestine; nevertheless, it may vary depending on its histological origin (lymphatic, mesothelial, enteric, urogenital, mature cystic teratoma, infectious, or trauma non-pancreatic pseudocysts) $)^{4,5,8,9}$.

Its unspecific clinical and incipient evolution makes acute presentation unusual; however, it can manifest as chronic abdominal pain (55\%-81\%), palpable mass (44\%-61\%), distension (17\%-61\%), nausea and vomiting $(45 \%)$, constipation $(27 \%)$, and diarrhea $(6 \%)^{5,6,8,10}$. Hence, the absence of obvious signs and symptoms makes diagnosis difficult; therefore, most described cases have been diagnosed incidentally, only evidenced by imaging studies ${ }^{2-7}$.

Hereunder, we present the case of an adolescent who attended the emergency service on two occasions due to abdominal pain. In the last internment, during the physical examination, the presence of a palpable tumor was evidenced, which, at first, was diagnosed as the probable presence of an ovarian cyst, and only after imaging studies were the possibility of a mesenteric cyst considered.

\section{Clinical case}

The patient, a 14-year-old female without any relevant background, arrived with sudden onset and continuous

\section{Correspondence:}

*Julio C. López-Valdés

E-mail: jc.lopz@live.com

Available online: $28-06-2021$

Date of reception: 29-11-2020

Date of acceptance: 02-03-2021 DOI: 10.24875/RMU.20000085

Medicina Universitaria. 2021;23(2):57-60 www.medicinauniversitaria.org

1665-5796/@ 2021 Universidad Autónoma de Nuevo León. Published by Permanyer. This is an open access article under the CC BY-NC-ND license (http://creativecommons.org/licenses/by-nc-nd/4.0/).
} 


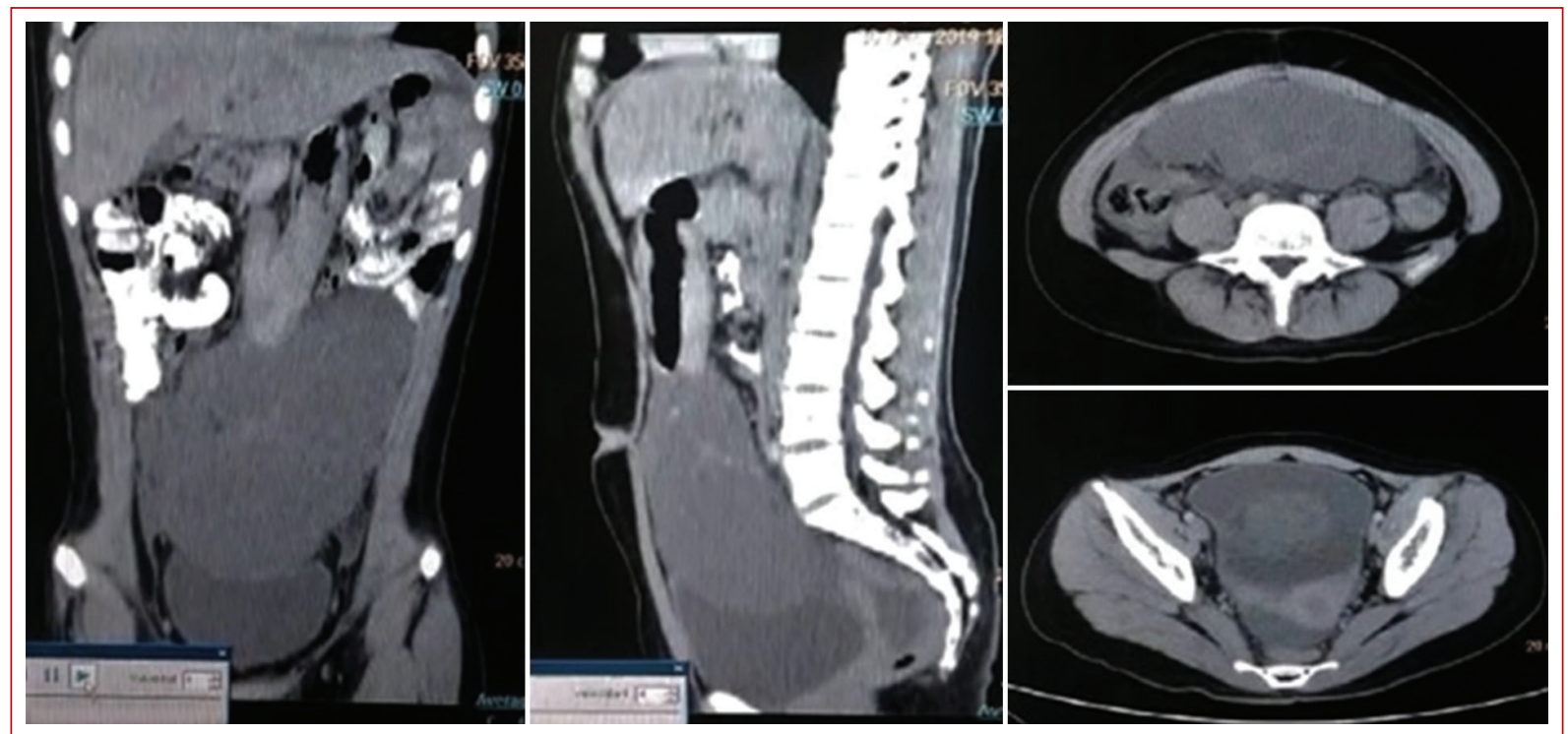

Figure 1. Abdominal cat scan with contrast. Cystic tumor from the pelvis to left flank of approximately $20 \times 15 \mathrm{~cm}$ septate with a density of $16 \mathrm{HU}$, a minimal amount of perihepatic and peri-splenic fluid, and a bilateral renal pyelocalistasia of $16 \mathrm{~mm}$, predominantly left.

abdominal pain in the left iliac fossa, with an $8 / 10$ intensity on the VAS pain scale, which was generalized on the $4^{\text {th }}$ day of evolution. There was no improvement with the intake of NSAIDs. It was accompanied by nausea and vomiting of gastrointestinal content on four occasions, constipation and abdominal distension, and hiporexia. During the physical examination, the following vital signs were found: blood pressure 100/60, height ratio 78 bpm, RF 24 rpm, temperature 37.0, weight: 44250 , height $146 \mathrm{~cm}$, and body mass index: $20 \mathrm{~kg} / \mathrm{m}^{2}$. On physical examination was found with a good coloration of skin and teguments, neck without alterations, and thorax with an adequate presence of respiratory movements. Cardiac noises with good intensity and tone, abdomen with a slight increase in volume in the lower region, with normal peristalsis; at palpation, hyperesthesia, hyperbaralgesia, and pain at medium profuse palpation in the epigastrium and both hypochondrium. A stone-like, movable and painful tumor was perceived, not adhered to deep layers, of about 15 $\mathrm{cm} \times 15 \mathrm{~cm}$, without the presence of data suggestive of peritoneal irritation, with tympanism in the left flank and fossa, and genitourinary according to age and gender, without alterations.

Laboratory studies performed at the moment are described next: hemoglobin: $14.10 \mathrm{~g} / \mathrm{dl}$, hematocrit: $40.80 \%$, leucocytes: $9.37 \times 10^{3} \mu \mathrm{L}$, platelets: $347 \times 10^{3}$ $\mu \mathrm{L}$, neutrophils: $72 \%$, glucose: $88 \mathrm{mg} / \mathrm{dl}$, urea: $29, \mathrm{BUN}$ :
13, creatinine: 0.99, Na: 139, K: 4.87, Cl: 103.60, Ca: 9.52, TP: 11.4, TPT: 31.7, INR: 1.0, and immunological pregnancy test: negative.

Pelvic ultrasound revealed a normal liver, gallbladder, pancreas, spleen, kidney, and uterus. The right ovary was $32 \mathrm{~cm} \times 18 \mathrm{~cm} \times 36 \mathrm{~mm}$, for a volume of $11 \mathrm{cc}$; the left ovary had a habitual location and defined borders, measuring $24 \mathrm{~mm} \times 13 \mathrm{~mm} \times 25 \mathrm{~mm}$, for $4 \mathrm{cc}$, with the parenchyma in a follicular pattern.

At a supravesical level, a cystic lesion of lobulated borders was observed with internal septa and floating fine echoes and an extension toward the mesenteric region. After applying Doppler without vascularization, it was shown to have an approximate volume of 308 ccs. A contrasted tomography of the abdomen was requested with a diagnostic suspicion of a mesenteric cyst versus lymphatic malformation (Fig. 1).

Given the discoveries in the imaging studies, surgical intervention was decided on, in which the following findings were reported: a mesenteric cyst of $30 \mathrm{~cm}$ in length, with clear fluid in its interior, was attached to the greater curvature of the stomach and located in the entire abdomen and pelvic cavity, with a tendency toward the left iliac fossa (Fig. 2).

After 3 days of intrahospital stay without eventualities, discharge was decided on, with a subsequent follow-up consultation with the histopathological study results (Fig. 3). 


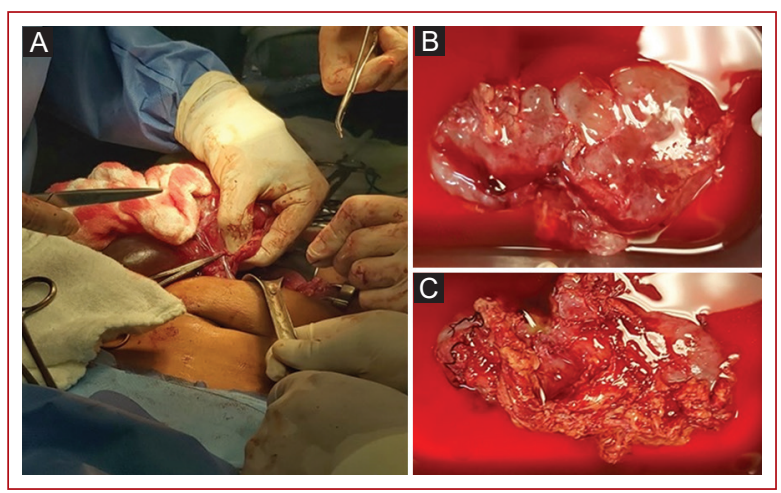

Figure 2. A: surgical event. B-C: mesentery cyst; irregular cystic tumor of irregular shape measuring $14.4 \mathrm{~cm} \times 8.3 \mathrm{~cm} \times 7.1 \mathrm{~cm}$, smooth external surface, with omentum of $15.0 \mathrm{~cm} \times 12.7 \mathrm{~cm} \times 10.0 \mathrm{~cm}$, firmly adhered, to the section of soft consistency, multilocular, clear fluid outlet, 0.1-0.5 cm wall, with a smooth inner surface.

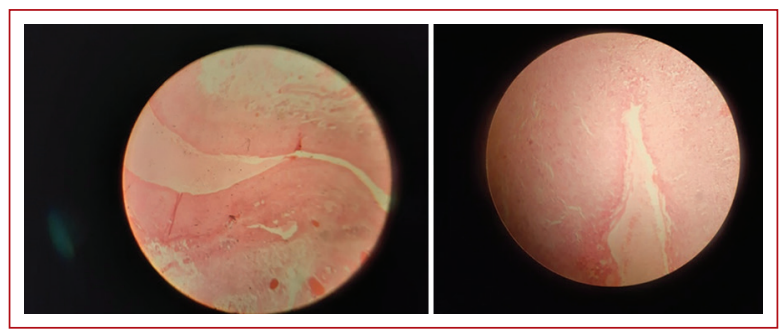

Figure 3. Slides corresponding to histopathological study.

\section{Discussion}

Today, despite the low frequency linked to mesenteric cysts, there has been a considerable rise in the number of reported cases, thanks perhaps to the cosmopolitan access to a greater number of imaging studies.

This report is an example of a case proper to this benign entity since it concurs with the epidemiological characteristics commonly described when presenting in a female in her twenties and a cyst of measurements within those reported $(<30 \mathrm{~cm})^{4,5}$. Nevertheless, the particularity described in this case is the site of the cyst, being the greater curvature of the stomach. As previously mentioned, it is usually found in two-thirds of the small intestine followed by the large intestine $e^{5-11}$. We ought to stress the fact that, even though its etiology is not completely clear, the most accepted theory describes a proliferation of the ectopic lymphatic tissue, which does not communicate with the central lymphatic system ${ }^{9,10}$; nevertheless, there are different hypotheses described (Table 1).
Table 1. Principal hypotheses regarding the origin of mesentery cysts

\begin{tabular}{|l|l|}
\hline Principal hypotheses \\
\hline 1 & $\begin{array}{l}\text { The rupture of lymphatic vessels and the consequent } \\
\text { formation of granular tissue after lymph extravasation }\end{array}$ \\
\hline 2 & Abnormal lymphatic vessels without a drainage path \\
\hline 3 & Lack of fusion of the mesentery folds \\
\hline 4 & Secondary to abdominal trauma \\
\hline 5 & Lymphatic degeneration \\
\hline
\end{tabular}

Just as in most cases and isolated reports, our patient presented abdominal pain as the main symptom, which is the main reason for consultation. In addition, during the physical examination, a palpable abdominal tumor was found, as in most patients. Quite often, acute abdominal pain is presented as a complication consequent to infection, hemorrhage, torsion, rupture, or intestinal obstruction; in our case, this was not the case.

While the treatment of choice is a total incision of the cyst whenever possible, current surgical management tendencies in pediatric patients are through laparoscopy. Drainage and aspiration of the cyst are not recommended due to the high rate of recurrences. Likewise, the mesenteric cyst's relationship with the main abdominal vessels should be taken into consideration; a careful and precise dissection should be performed. It is even necessary to assess the need for a segmentary intestinal resection in case it is not possible to preserve blood supply, especially in giant cysts in which excision may be difficult ${ }^{1-5,12-14}$.

In our case, total open excision was accomplished without the need for resection of adjacent organs.

\section{Conclusions}

Despite this surgical entity's low incidence, theoretical instruction is necessary for its excision due to the high probability of recurrence or malignancy. Moreover, this benign entity's existence ought to be known, given the high probability of incidental findings during patient assessment with chronic abdominal processes, being even greater in pediatric and adolescent patients.

\section{Conflicts of interest}

The authors declare not to have any conflicts of interest (based wage worker or honorarium, consultant, counseling, research studies, participation in the development of pharmaceuticals, or stock in companies). 
Moreover, they commit to inform in a timely fashion and before implementation if they were to establish a commitment with pharmaceutical industries and/or similar organizations, which may influence or generate a conflict of interest in the decision-making process.

\section{Funding}

The authors declare not to have received funds from any private or government institution for the development of this study.

\section{Ethical disclosures}

Protection of human and animal subjects. The authors declare that no experiments were performed on humans or animals for this study.

Confidentiality of data. The authors declare that they have followed the protocols of their work center on the publication of patient data.

Right to privacy and informed consent. The authors have obtained the written informed consent of the patients or subjects mentioned in the article. The corresponding author is in possession of this document.

\section{References}

1. Asgharnia M, Rahbar T, Dalil Heirati SF. Mesenteric cysts: a rare case. Clin J Obstet Gynecol. 2019;2:67-70.

2. Tan JJ, Tan KK, Chew SP. Mesenteric cysts: an institution experience over 14 years and review of literature. World J Surg. 2009:33:1961-5.

3. Prakash A, Agrawal A, Gupta R, Sanghvi B, Parelkar S. Early management of mesenteric cyst prevents catastrophes: a single centre analysis of 17 cases. Afr J Paediatr Surg. 2010;7:140-3.

4. Fernández-lbieta M, Rojas-Ticona J, Martinez-Castaño P, Rios PR, Villamil V, Vallejo OG, et al. Quistes mesentéricos en la edad pediátrica: qué son en realidad? An Pediatr (Barc). 2015;82:e48-51.

5. Makhija D, Shah H, Tiwari C, Jayaswal S, Khedkar K, Waghmare M. Mesenteric cyst(s) presenting as acute intestinal obstruction in children: three cases and literature review. J Ped Surg Case Rep. 2013;1:84-6.

6. Leung BC, Sankey R, Fronza M, Maatouk M. Conservative approach to the acute management of a large mesenteric cyst. World $\mathrm{J}$ Clin Cases. 2017;5:360-3.

7. Marte A, Papparella A, Prezioso M, Cavaiuolo S, Pintozzi L. Mesenteric cyst in 11-year old girl: a technical note. Case report. J Ped Surg Case Rep. 2013;1:84-6.

8. Kim SI, Kim YD, Lee HS, Jee BC. A case of mesenteric cyst confused with ovarian endometrioma. Korean J Obstet Gynecol. 2012;55:683-6.

9. Miljković D, Gmijović D, Radojković M, Gligorijević J, Radovanović Z. Mesenteric cyst. Arch Oncol. 2007:15:91-3.

10. Pithawa AK, Bansal AS, Kochar SP. Mesenteric cyst: a rare intra-abdominal tumour. Med J Armed Forces India. 2014;70:79-82.

11. Miliaras S, Trygonis S, Papandoniou A, Kalamaras S, Trygonis C, Kiskinis $D$. Mesenteric cyst of the descending colon: report of a case. Acta Chir Belg. 2006;106:714-6.

12. Jain V, DeMuro JP, Geller M. A case of laparoscopic mesenteric cyst excision. Case Rep Surg. 2012;2012:594095.

13. Aguirre SV, Mercedes Almagro M, Romero CA, Romero SS, Molina GA Buenaño RA. Giant mesenteric cyst from the small bowel mesentery in a young adult patient. J Surg Case Rep. 2019;2019:riz002.

14. Ünlüer EE, Ünlüer S, Sahin Y, Kamer KE, Karagöz A, Tan GC. An uncommon cause of abdominal pain: mesenteric cyst. Interv Med Appl Sci. 2016;8:23-5. 